Article

\title{
Does Green Innovation promote New Urbanization develop- ment? From the perspective of coupling coordination between Green Innovation and New Urbanization
}

\author{
Weixiang $\mathrm{Xu}{ }^{1}$, Lindong Ma ${ }^{2,3}{ }^{*}$, Yuanxiao Hong ${ }^{3}$, Xiaoyong Quan ${ }^{3}$ \\ 1 School of Economics, Zhejiang University of Technology, Hangzhou, China; xwq02@163.com \\ 2 School of Management, Zhejiang University of Technology, Hangzhou, China; lin- \\ dong_ma@zjut.edu.cn \\ 3 Xingzhi college, Zhejiang Normal University, Jinhua, China; hyx021@zjnu.cn; qxx@zjnu.cn; \\ * Correspondence: lindong_ma@zjut.edu.cn
}

\begin{abstract}
Green innovation has become the mainstream of the era, and New Urbanization is an inevitable choice in the process of urbanization in China. Focusing on the topics of green innovation and new urbanization, much work has been done to find their factors respectively while the relationship between the two remains to be explored. Hence, in this article, representative indicators of new urbanization and green innovation are selected to study the Yangtze River Delta City Group from the perspective of both the entire urban agglomeration and a single city, in terms of time and space, using the entropy method and the coupling model. The results show that (1). Green innovation promotes the new urbanization development and there is a synergistic effect between the two systems. (2). The level of economic development is an important factor that affects the degree of coupling degree and coordination degree between the two interactions, and its influence is better than the spatial effect. (3). Green innovation and new urbanization have positive spatial autocorrelation and regional agglomeration (there are High-High, Low-Low, and HighLow collections).
\end{abstract}

Keywords: green innovation; new urbanization; coupling model; coupling coordination degree; temporal and spatial difference; Yangtze River Delta City Group

\section{Introduction}

Since the reform and opening-up, China's economy has been on an upward trend of rapid growth. But it can hardly last with the extensive economic growth model, which relies on production factors like labor, resources, etc., and comes at the expense of the environment. This has caused the abuse of environmental resources and non-renewable energy, and the arbitrary discharge of wastewater and waste gas, resulting in environmental damage and a serious waste of resources and energy. It has prompted the Chinese government and people to explore a sustainable economic and social development model. The economic conference held by the CPC Central Committee at the end of 2013 clarified that green ecological development is the core measure of China's new urbanization strategy [1]. The "19th National Congress" of the party further put forward the concept of comprehensive green development and pointed out that it is necessary to build a new urbanization pattern taking city group as the main body with coordinated development of large, medium, and small cities [2], implement the regional coordinated development strategy and organically integrates the concept of green development with green development methods and daily lifestyle. For this reason, the topics of green development, green economy, green innovation development have been discussed intensively in the academic field [3]. Among them, the new urbanization, which is used to evaluate the level of green urbanization, and the green innovation, which measures the quality of green development 
and innovation capabilities, have been rapidly developed and enriched and studied indepth from multiple dimensions. However, few scholars discuss the relationship between green innovation and new urbanization. But in fact, the study of the relationship between the two is not only conducive to enriching the original theories but also has great guiding significance for the specific practice of China. At the same time, it also has an important theoretical and practical reference for other similar countries to environmentally friendly sustainable development.

Judging from the existing literature, most researches are focused on unilateral analysis through all kinds of models, for example, the impact of new urbanization development on economic growth [4], the mutual impact of the green innovation system and traditional urbanization [5,6], and the impact of environmental regulations on green innovation development and new urbanization level [7]. In addition, studies based on innovation and traditional urbanization have also drawn some useful conclusions. Grossman believed that urbanization should rely on technological progress and promote economic growth and urbanization through technological progress [8]. Wilson analyzed and concluded that scientific and technological innovation is the driving force for urbanization development [9]. Liu [10] believed that scientific and technological input can effectively promote the development of urbanization, and it varies with different regions. In turn, Jacobs [11] believed that urban development promoted the formation of the competitive market, accelerated the accumulation and diffusion of knowledge, and played a positive role in promoting scientific and technological innovation. The study of Rosenthal and Tappenner showed that urbanization leads to the expansion of city scale, enhances the agglomeration degree of industry and knowledge, and provides a favorable environment for scientific and technological innovation[12,13]. Summing up existing studies, scholars have discussed the interactive relationship between innovation and new urbanization to some extent, but they mainly focus on the qualitative analysis of the one-way influence relationship between the two, and lack of targeted quantitative analysis. There has not been a comprehensive and systematic study on the mutual coordination relationship between the two and its development trend. Therefore, the study of the relationship between green innovation and new urbanization and its time evolution process has much theoretical value and practical guiding significance.

The Yangtze River Delta city group is the sixth-largest urban agglomeration in the world, and the most dynamic and representative urban agglomeration in China [14]. At the same time, it is also the top priority of the high-quality development of the Yangtze River Economic Belt [15]. Its development law is representative and forward-looking. Therefore, the exploration in its development law and spatial correlation of the internal coupling coordination between the green innovation and the new urbanization development based on the Yangtze River Delta city group has typical and represents the trend of future development in China.

This study makes the following contributions to enriching this topic. First, it measures the new urbanization and green innovation level in the Yangtze River Delta city group with the entropy method firstly. Second, the relationship between the new urbanization development and green innovation level is measured and analyzed through coupling degree, relative coupling degree, and coupling coordination degree. Finally, an analysis of the spatial correlation between the green innovation level and new urbanization development is conducted.

The rest of this article is arranged as follows: "Materials and Methods" introduce the Yangtze River Delta City Group, and index system and describes the selected research methods. In "Results", an empirical study is provided for the new urbanization and green innovation in Yangtze River Delta City Group from 2010 to 2018. Finally, "Discussion" explains the internal mechanism of green innovation and new urbanization, as well as the relationship with space and economic development. "Conclusions" and comes up with the countermeasures. 


\section{Materials and Methods}

\subsection{Introduction to the Yangtze River Delta City Group}

The Yangtze River Delta city group is east of China located in the Yangtze River Economic Belt and is centered on Shanghai, with Hangzhou, Nanjing, and Hefei as the subCenters (Figure 1). It consists of Nanjing, Wuxi, Changzhou, Suzhou, Nantong, Yangzhou, Zhenjiang, Yancheng, Taizhou(J) in Jiangsu province, Hangzhou, Ningbo, Huzhou, Jiaxing, Shaoxing, Jinhua, Zhoushan, Taizhou(Z) in Zhejiang province, and 26 cities in Anhui Province, including Hefei, Wuhu, Ma'anshan, Tongling, Anqing, Chuzhou, Chizhou, and Xuancheng, etc. It is located in the alluvial plain across which the Yangtze River enters the sea, with a land area of 211.7 thousand square kilometers, accounting for about $2.2 \%$ of China. By the end of 2019, the permanent population is about 151 million, accounting for about $11 \%$ of the country, and the regional GDP is 21.15 trillion yuan, occupying about $25 \%$ of China. The "Development Plan for the Yangtze River Delta City Cluster " specifies that it will be built into the most economically dynamic resource allocation center, a global influential technological innovation highland, an important global modern service industry and advanced manufacturing center, an important international gateway in the AsiaPacific region, a pioneer in the new round of reform and opening up, and a beautiful China construction demonstration zone [16]. By 2030, it will be fully built into a worldclass urban agglomeration with global influence and become the most influential and driving area in terms of ecological environment, innovation development, and coordinated urban-rural development. It is the most representative of innovation in China and the benchmark for new urbanization [17]. Therefore, taking it as the research object has good representativeness and the trend of future development. But it's unknown whether or not and how green innovation is conducive to new urbanization. It will illustrate and influence new urbanization and regional sustainable development. As a typical test base for China, its success will, directly and indirectly, affect China's future policies and development strategies. Similarly, it will also provide a reference for the sustainable development of other countries and regions.

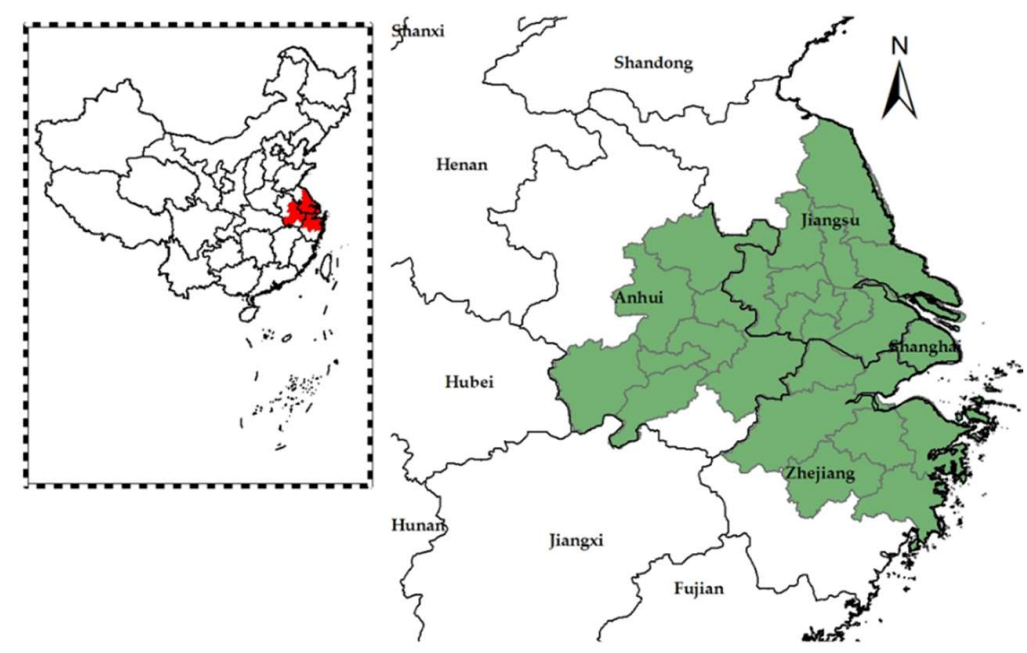

Figure 1. Location of the study area in China

\subsection{Constructing index system}

To accurately evaluate the degree of coordination between the green innovation system and new urbanization system, and to reflect the interaction between the indicators in each system, by referring to the existing systems and indicators in the literature, we combine the characteristics of these two systems to construct the evaluation index system in Table 1 below. 
Regarding the indicators for measuring regional green innovation system, to reflect the level of green innovation comprehensive and systematic, it was measured from the perspective of regional investment, environment, and efficiency. It starts from three aspects: innovation input, output, and environment. Innovation input mainly includes human resources, capital, and energy, and output indicators mainly include patent authorization and economic improvement. To better reflect the improvement of the entire economy and society, the economic improvement is expressed as GDP per capita. Based on the existing literature and the availability and accuracy of data, the proportion of spending on science and technology in government spending and the volume of books in public libraries represents a regional innovation environment. Therefore, based on the original scientific and technological innovation measurement indicator system, green innovation has deliberately added innovative environmental, pollutants, environmental and economic conditions. Its purpose is to better reflect the science, greenness, and sustainability of innovation.

In the new urbanization system, it is a comprehensive evaluation system that is different from the traditional evaluation of urbanization level only based on population. It includes six parts [18-24], which are population, economy, space, society, ecology, and environmental pollution. The population urbanization rate is mainly indicated by the proportion of the urban population in the total population of the region through the traditional accounting method. Economic urbanization rate mainly reflects the structural proportion of agriculture and non-agriculture and their compositions and is expressed by the proportion of the output value of the secondary and tertiary industries in the total output value. The spatial urbanization rate is measured by the conversion of land nature, that is, the degree to which rural and agricultural land is converted into urban construction land. Specifically, it is measured by the proportion of built-up area in the total land area of the city district. Society urbanization which is the development level of urban and rural economy and society and people's lives is measured by the total retail sales of social consumer goods per capita of urban and rural people. The ecological urbanization rate is measured by the park green area per capita. According to the actual situation of China, the comprehensive recycling rate of solids and other wastes is above $95 \%{ }^{1}$. Therefore, this article selects the main pollution sources-industrial wastewater and industrial sulfur dioxide $\left(\mathrm{SO}_{2}\right)$ emissions as environmental pollution. New urbanization is a comprehensive system that is in line with social development. Therefore, this research is based on the previous research and well takes population, economic, spatial, social ecology, and environment into consideration, showing science and sustainable development of new urbanization.

Table 1. Green Innovation - New Urbanization system evaluation index system

\begin{tabular}{clcc}
\hline \multicolumn{1}{c}{ Index } & & Property & References \\
\hline (a) Green innovation & & & Zhang [25] \\
Innovation input & R\&D personnel full-time equivalent & Ming [26] & + \\
& R\&D expenditure & + & Feng [27] \\
Innovation output & The number of domestic granted invention patents & + \\
& GDP per capita & + \\
\hline \multirow{2}{*}{ Innovation environment } & The proportion of spending on science and technology & + \\
& The volume of books in public libraries & \\
\hline
\end{tabular}

\footnotetext{
1 According to the data of the 2018 statistical annual report published by the provinces and cities of the Yangtze River Delta City Group
} 


\section{(b) New urbanization}

urbanization of

population

Economic urbanization

Spatial urbanization

Social urbanization

Ecological urbanization

Environment pollution
The proportion of the urban population in the total population

The non-agricultural economy as a proportion of GROSS domestic product

Zhao [28]

The proportion of built-up area in the total area of the city district

Retail sales of consumer goods per capita

$+\quad$ Jiang [21]

Park green area per capita

$+$

Zhang [22] wastewater disposal SO2 emissions

\subsection{Data sources}

Yangtze River Delta City Group is a typical demonstration site for academic research in China and the main data were taken from the "Statistical Yearbook of Jiangsu Province", "Statistical Yearbook of Zhejiang Province", "Statistical Yearbook of Anhui Province", "Shanghai Statistical Yearbook", "Statistical Yearbook of China's Cities" and statistical yearbooks of cities in the Yangtze River Delta (2011-2019), National Economy and Society Development Statistics Bulletin (2010-2018). The spatial analysis scale is the Yangtze River Delta city area unit (a total of 26), and the administrative boundary data is taken from the official atlas published by each province.

\subsection{Research model}

The entropy method is an objective-weighting method, and the use to determine the index weight has a high degree of credibility. The index is divided into a positive index and a negative index. The larger the positive index value is, the more favorable it is for the system, while the larger the negative index value is, the more unfavorable it is for the system. And since the dimensions of the original variables, we first standardize the selected indicators as follows:

$$
\text { Positive index: } X_{i j}^{\prime}=\frac{X_{i j}-\min \left(X_{i j}\right)}{\max \left(X_{i j}\right)-\min \left(X_{i j}\right)}
$$

$$
\text { Negative index: } X_{i j}^{\prime}=\frac{\max \left(X_{i j}\right)-X_{i j}}{\max \left(X_{i j}\right)-\min \left(X_{i j}\right)}
$$

Where $X_{i j}$ represents the comprehensive score of the jth in a year I, max $\left(X_{i j}\right)$ is the maximum value of the $j$ th index, $\min \left(X_{i j}\right)$ is the minimum value of the $j$ th index, and $X^{\prime}{ }_{i j}$ is the normalized value of $X_{\mathrm{ij}}$.

$$
\begin{aligned}
Y_{\mathrm{ij}} & =\frac{X_{\mathrm{ij}}^{\prime}}{\sum_{i=1}^{m} X_{\mathrm{ij}}^{\prime}}\left(0 \leq Y_{\mathrm{ij}} \leq 1\right) \\
e_{j} & =-\frac{1}{\ln m} \sum_{i=1}^{m} Y_{i j} \ln Y_{i j} \\
d_{j} & =1-e_{j} \\
w_{j} & =\frac{d_{j}}{\sum_{j=1}^{m} d_{j}}
\end{aligned}
$$


where $Y_{i j}$ represents the proportion of the index value of the jth index in year $i . e_{j}$ and $d_{j}$ are the entropy value and utility value of the indicator $j$, and $w_{j}$ stands for the weight of the indicator $\mathrm{j}$.

$$
U=\sum_{i=1}^{m} w_{j} X_{\mathrm{ij}}^{\prime}
$$

Where $U$ represents the comprehensive score of the system. The larger the comprehensive score, the higher the degree of development of the system.

\subsection{Coupling coordination degree model}

The coupling degree model is a typical application of hard science principles in the field of soft science. Because of its clear meaning and simple calculation, this model has been widely used in geographical research [29]. Coupling mainly refers to the phenomenon in which two or more systems affect each other through various interactions. Drawing lessons from related models of coupling coordination degree in physics, the expression of the coupling degree model generally has two forms. Given $n \geq 2$ systems, $U_{i} \geq 0$ is used to represent the evaluation value of the system $\mathrm{Si}$, then the generalized calculation formula of the coupling degree can be expressed as formula (3-2) and formula (3-3):

$$
\begin{aligned}
& C_{1}\left(U_{1}, U_{2}, \ldots, U_{n}\right)=n \times\left[\frac{U_{1} U_{2} \ldots U_{n}}{\left(U_{1}+U_{2}+\ldots+U_{n}\right)^{n}}\right]^{\frac{1}{n}} \\
& D=\sqrt{C T}, T=\alpha_{1} U_{1}+\alpha_{2} U_{2}+\ldots+\alpha_{n} U_{n}
\end{aligned}
$$

Where $C_{1}$ and $C_{2}$ represent two kinds of coupling degrees. When $n=2, C_{1}=C_{2}$, and when $n>2,0 \leq C_{1} \leq C_{2} \leq 1$ [26]. $D$ is the coupling coordination degree, $T$ is the comprehensive coordination index $\alpha_{1}, \alpha_{2}, \ldots, \alpha_{\mathrm{n}}$ are the undetermined coefficients. Referring to the existing research results [30-34] and combined with the reality, this paper takes $\alpha_{1}=\alpha_{2}$ $=, \ldots,=\alpha_{\mathrm{n}}=1 / \mathrm{n}$.

So far, there are no uniform criteria for the coordination degree [35]. The existing research pays more and more attention to the green innovation efficiency and new urbanization efficiency in recent years, but most of them are limited within the scope of a single efficiency factor. It is still a blank about the research on the coordination coupling degree of the two, whether it is based on the overall city group or a single city. As a result, with the reference to previous studies [36], the coordination degree is divided into five categories, as shown in Table 3.

Table 3. Classification criteria for coordination

\begin{tabular}{l|l}
\hline Coordination interval & Coordination level \\
\hline $0.0 \leq \mathrm{D}<0.10$ & General disorder \\
\hline $0.10 \leq \mathrm{D}<0.2$ & Preliminary disorder \\
\hline $0.2 \leq \mathrm{D}<0.3$ & Preliminary coordination \\
\hline $0.4 \leq \mathrm{D}<0.7$ & Moderate coordination \\
\hline $0.7 \leq \mathrm{D}<1.0$ & Quality coordination \\
\hline
\end{tabular}

\subsection{Relative coupling development model}

The coupling coordination degree can only reflect the coordination between green innovation and new urbanization, but it is difficult to explain the relative development degree between the two systems. The relative development degree model [37] is adopted to determine the relative development coefficient $(\varphi)$ of the system.

$$
\varphi=U_{i} / U_{u}
$$


where, $U_{i}$ and $U_{u}$ are the comprehensive development indexes of green innovation and new urbanization respectively. It is generally believed that $0<\varphi \leq 0.8$, the former lags behind the latter; If $0.8<\eta \leq 1.2$, they are considered to be synchronized and coordinated; When $\eta>1.2$, the former is ahead of the latter [38].

\subsection{Spatial autocorrelation analysis}

The spatial weight matrix is a prerequisite for spatial autocorrelation analysis, which is the basis for Moran's I statistical tests and model construction. $W_{\text {ij }}$ represents the spatial weights, which are mainly divided into spatial weights based on adjacency relationships and distance relationships. Considering economic relations and practical needs of research, the minimum threshold distance of the spatial weights based on the distance relationship was chosen for this study.

$$
\mathrm{W}_{\mathrm{ij}}= \begin{cases}1 & \text { bound }(i) \cap \text { bound }(j) \neq 0 \\ 0 & \text { bound }(i) \cap \operatorname{bound}(j)=0\end{cases}
$$

where bound (i) is the boundary of a spatial cell.

The Moran's Index is divided into Global Moran's I and Local Moran's I. Global Moran's I indicate whether there is agglomeration or anomaly in space, while local Moran's I indicate where there is an anomaly or where there is agglomeration. The expression of Global Moran's I is given by:

$$
I=\frac{N}{S_{0}} \frac{\sum_{i=1}^{N} \sum_{j=1}^{N} W_{i j}\left(y_{i}-\bar{Y}\right)\left(y_{j}-\bar{Y}\right)}{\sum_{i}^{N}\left(y_{i}-\bar{Y}\right)^{2}}
$$

Where $\mathrm{S}_{0}=\sum_{\mathrm{i}=1}^{\mathrm{N}} \sum_{\mathrm{j}=1}^{\mathrm{N}} \mathrm{W}_{\mathrm{ij}}, \bar{Y}=\frac{1}{N} \sum_{y=1}^{N} y_{i}$ and $y_{i}$ represent the observed value of region $\mathrm{i}$. $\mathrm{N}$ is the total number of all observation regions.

The expression of local Moran's I is:

$$
I_{i}=\frac{Y_{i}-\bar{Y}}{S_{i}^{2}} \sum_{j=1, j \neq i}^{N} W_{i j}\left(Y_{j}-\bar{Y}\right)
$$

\section{Results}

This paper uses Yangtze River Delta City Group as an example to explore whether green innovation can promote new urbanization development from time and space analysis and coupling coordination.

\subsection{The green innovation and new urbanization development in the Yangtze River Delta City Group}

3.1.1. An overview of the development of the Yangtze River Delta City Group in recent years

Yangtze River Delta City Group is the strongest regional area in terms of its economic aggregate and growth rate in China. From Figure 2, it is seen that its GDP per capita is 15370 dollars (2018), and China's 9770 dollars during the same period. During the study period, it maintained an average annual growth rate of $10.99 \%$, while China's domestic average growth rate during the same period was $7.80 \%$. Therefore, the Yangtze River Delta City Group is known as the compass, locomotive and barometer of China's economy and future development. The great economic development has brought extremely high economic benefits, but it has also caused Yangtze River Delta City Group to bear some serious ecological pressure [31], especially in some cities in Jiangsu province [35]. The number of companies with severe environmental risks ranks among the top in China, and coal consumption accounts for nearly $60 \%$ of primary energy consumption, forming an energy consumption structure based on coal and an industrial structure based on heavy chemicals [35]. Therefore, the study of the relationship between green innovation and new urbanization development highlights the actual and future development trend of China's development. 
3.1.2. Analysis of the green innovation and new urbanization system evaluation index

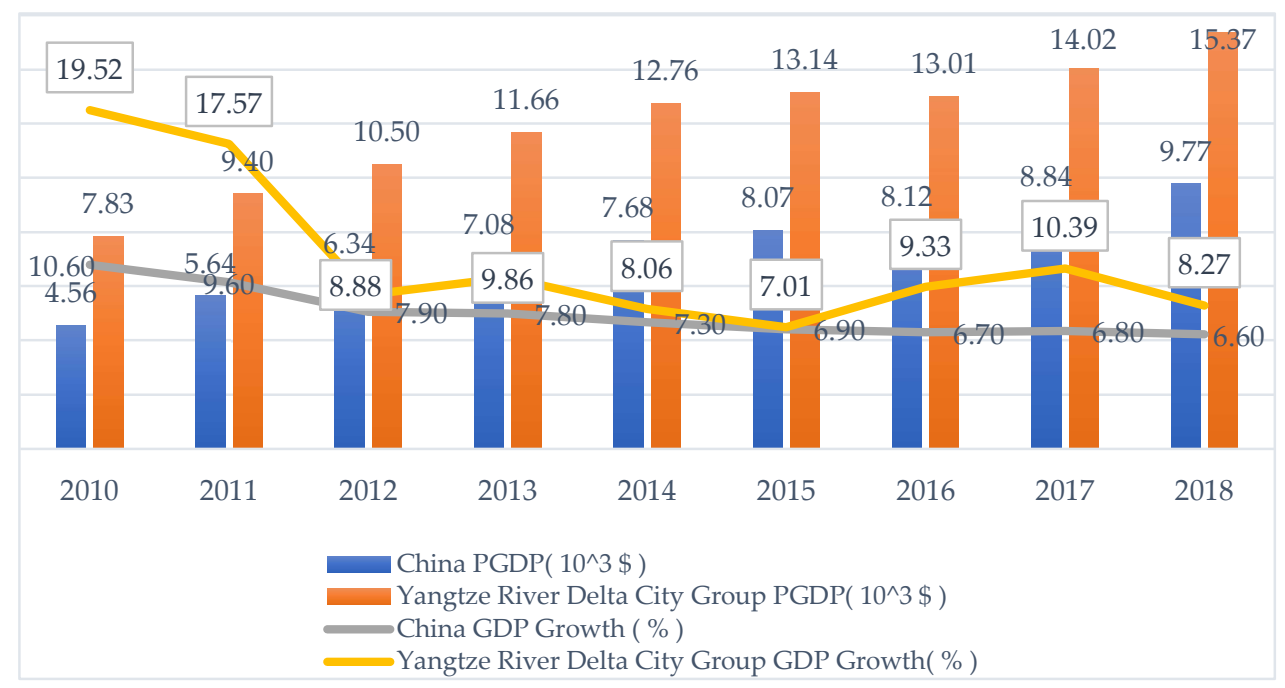

Figure 2. China and Yangtze River Delta City Group's GDP Growth

From Figure 3 it is seen that with the increased emphasis on green innovation in recent years, especially in some Chuck sides of core technology. In terms of green innovation, the annual growth of capital investment reached 15.58\% (From 165 billion yuan in 2010 to 501 billion yuan in 2018), which was far exceeding the economic growth rate of $10.99 \%$ (Figure 2) and indicators in social development rate (Table 3) of the same period. But the number of full-time equivalents of R\&D personnel have stayed roughly the same (From 1144610 man-year in 2010 to 1107385 man-year in 2018 and the average from 2010 to 2018 is 1320941 man-year). The number of domestic patents granted, which is an important indicator reflecting the innovation index, goes up in waves, increased by 1.323 . The proportion of successful patents application has a downward tendency in the recent 9 years. This suggests that innovation is no longer as productive as it used to be. This may be related to the stage of regional development and social development. The reduction of green innovation will affect the development of the entire regional innovation system, and may further affect the development of new urbanization.

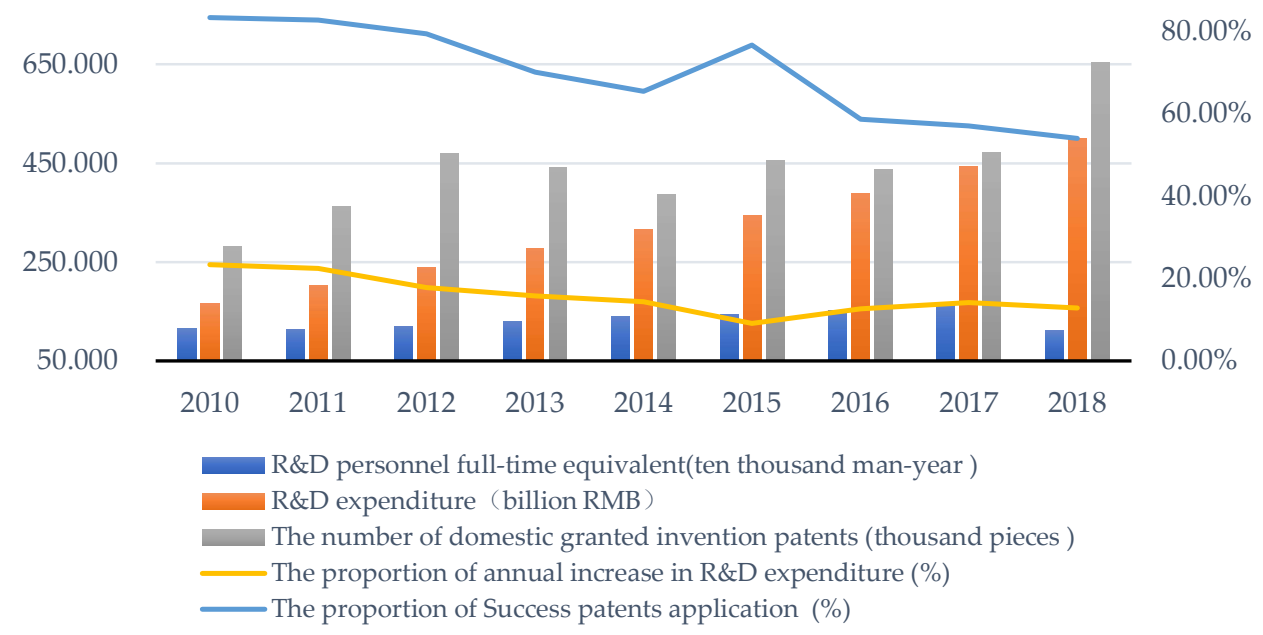

Figure 3. Yangtze River Delta City Group's Green Innovation Main Indicators 
New urbanization is a comprehensive and developmental system index. It consists of various sub-indexes. It includes people, economy, social, ecology, and environment, which is a new type of people-oriented and eco-environment protection, and adapt to the trend of future social development. Over the last decade or so, China's environmental governance has achieved relatively good results, especially in some regions. Wastewater disposal dropped from 5.4billion tons in 2010 to 3.4 billion tons in 2018 (table 3), and the $\mathrm{SO}_{2}$ emissions are a quarter of what it was, froming17.6 to 4.3 , which is the main representative of all exhaust gas. In terms of population and non-agricultural economy urbanization, it's the same. It has increased by an average of one percent a year in retail sales of consumer goods per capita, which is well below the rate of inflation over the same period in China. It is an important indicator of the ecological environment that is Park green area per capita increased over half a square meter. Due to the continuous expansion of some cities in recent years, the proportion of built-up areas has decreased. Generally speaking, the Yangtze River Delta city group is no exception. Of course, from every single city, there is a little difference.

Table 3. Yangtze River Delta City Group's new urbanization Index (2010-2018)

\begin{tabular}{lccccccccc} 
Index & $\mathbf{2 0 1 0}$ & $\mathbf{2 0 1 1}$ & $\mathbf{2 0 1 2}$ & $\mathbf{2 0 1 3}$ & $\mathbf{2 0 1 4}$ & $\mathbf{2 0 1 5}$ & $\mathbf{2 0 1 6}$ & $\mathbf{2 0 1 7}$ & $\mathbf{2 0 1 8}$ \\
\hline $\begin{array}{l}\text { Waste water disposal (billion } \\
\text { tons) }\end{array}$ & 5.386 & 4.927 & 4.712 & 4.507 & 4.307 & 4.340 & 3.794 & 3.508 & 3.429 \\
$\begin{array}{l}\text { SO2 emissions (hundred } \\
\text { thousand tons) }\end{array}$ & 17.606 & 17.781 & 16.787 & 15.973 & 13.297 & 13.921 & 7.577 & 5.307 & 4.259 \\
$\begin{array}{l}\text { The proportion of urban } \\
\text { population in the total population } \\
\text { (\%) }\end{array}$ & 59.113 & 63.011 & 62.823 & 62.641 & 62.462 & 62.290 & 62.133 & 61.982 & 61.838 \\
$\begin{array}{l}\text { Non-agricultural economy as a } \\
\text { proportion of GDP (\%) }\end{array}$ & 89.216 & 91.591 & 91.529 & 91.469 & 91.415 & 91.362 & 91.311 & 91.264 & 91.220 \\
$\begin{array}{l}\text { The proportion of built-up area in } \\
\text { the total area of city district (\%) }\end{array}$ & 6.520 & 6.432 & 6.371 & 6.309 & 6.248 & 6.187 & 6.127 & 6.067 & 6.008 \\
$\begin{array}{l}\text { Retail sales of consumer goods } \\
\text { per capita (ten thousand RMB) }\end{array}$ & 2.457 & 2.849 & 2.840 & 2.831 & 2.822 & 2.812 & 2.802 & 2.791 & 2.778 \\
$\begin{array}{l}\text { Park green area per capita } \\
\text { (sq.m.per.person) }\end{array}$ & 13.549 & 13.879 & 13.905 & 13.934 & 13.967 & 14.003 & 14.031 & 14.062 & 14.095
\end{tabular}

3.1.3. Analysis of green innovation and new urbanization development

To reflect the green innovation and new urbanization development more clearly, we use the system comprehensive score (formula 7) to reflect the development degree of green innovation and the new urbanization system. From table 4, 2010 to 2018, the comprehensive scores of Yangtze River Delta City Group's green innovation and new urbanization system were on the rise, and the green innovation system has been growing for a long time and it is growing fast. Although the new urbanization system has also been growing, the growth rate is slower than the green innovation system, slower down gradually. According to the Relative development model and related discussions, $\varphi$ reached its maximum value from 0.877 at the beginning to 1.089 in 2017 . During the study period, the green innovation system developed faster than the new urbanization system (Figure 4 ), but the two systems were not generally out of sync and coordination. From the coupling degree (C) can also be seen to always stay within the 0.4 range fluctuate $10 \%$. 
Table 4. Statistical discriptions of Yangtze River Delta City Group from 2010 to 2018

\begin{tabular}{cccccc}
\hline Year & $\mathrm{U}_{\mathrm{i}}$ & $\mathrm{U}$ & $\boldsymbol{C}$ & $\mathrm{C}$ & $\mathrm{D}$ \\
\hline 2010 & 0.00293 & 0.00334 & 0.87669 & 0.4281 & 0.14785 \\
\hline 2011 & 0.00326 & 0.00352 & 0.92450 & 0.43925 & 0.15354 \\
\hline 2012 & 0.00371 & 0.00376 & 0.98560 & 0.44674 & 0.15900 \\
\hline 2013 & 0.00409 & 0.00402 & 1.01783 & 0.45006 & 0.16317 \\
\hline 2014 & 0.00430 & 0.00428 & 1.00637 & 0.45163 & 0.16609 \\
\hline 2015 & 0.00452 & 0.00449 & 1.00642 & 0.44899 & 0.16783 \\
\hline 2016 & 0.00499 & 0.00477 & 1.04768 & 0.45018 & 0.17158 \\
\hline 2017 & 0.00548 & 0.00503 & 1.08945 & 0.45311 & 0.17522 \\
\hline & 0.00519 & 0.00526 & 0.98627 & 0.45675 & 0.17674 \\
\hline
\end{tabular}

( $U_{i}$ represents the level of the green innovation system; $U_{u}$ represents the level of the new urbanization development; $\varphi=U_{\mathrm{i}} / \mathrm{U}_{\mathrm{u}}$ represents the ratio of green innovation to new urbanization development; $C$ represents the degree of coupling between green innovation system and new urbanization development system; D represents the degree of coupling coordination between green innovation system and new urbanization development system; )

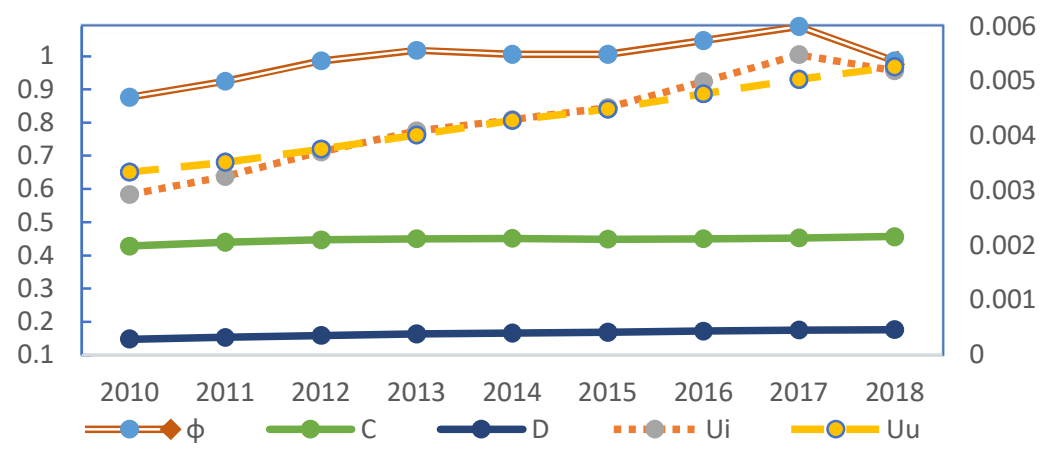

Figure 4. Yangtze River Delta City Group's innovation Some Indicators

\subsection{The green innovation and the new urbanization coupling and coordination analysis} from each city of the Yangtze River Delta City Group

\subsubsection{Coupling and coordination index}

To further study the impact of green innovation on new urbanization, the coupling degree (C) and coordination degree (D) of 26 cities for 2010 to 2018 in Yangtze River Delta City Group were calculated by using formula (8) and (9). It can be seen from Table 5 that the coupling degree has a similar trend of gradual increase on the whole. However, 7 cities (Shanghai, Wuxi, Suzhou, Nantong, Hangzhou, Ningbo, and Hefei.) of the city group have declined, Yancheng and Tongling remain unchanged. From the perspective of coupling coordination degree, the city group's overall upward trend is unstoppable. 
Among them, 25 cities are on the rise, while Jiaxing reached its peak in 2017 (0.2224), so 2018 has fallen a little $(0.1957$ - 0.1912). The coordination degree of Nanjing has improved the fastest (0.1748) and Nanjing is the only city among the 8 cities $^{2}$ in the Yangtze River Delta with a GDP of more than one trillion yuan whose coupling degree and coupling coordination degree have improved during the study period.

Since 2010, coupling between the two subsystems has been improved, and the degree for each city had been stable from 2012 to 2018, maintaining around 0.5. In contrast, the difference interval of coordination degree between the two subsystems in each city is much larger than the difference interval of coupling degree, and most cities had reached higher-level coordination by 2018.

Table 5. Statistical descriptions of Yangtze River Delta City Group from 2010 to 2018

\begin{tabular}{|c|c|c|c|c|c|c|c|c|c|c|}
\hline Name & & 2010 & 2011 & 2012 & 2013 & 2014 & 2015 & 2016 & 2017 & 2018 \\
\hline \multirow[t]{2}{*}{ Shanghai } & $\mathrm{C}$ & 0.4927 & 0.4861 & 0.4823 & 0.4766 & 0.4741 & 0.4700 & 0.4628 & 0.4567 & 0.4626 \\
\hline & $\mathrm{D}$ & 0.2220 & 0.2259 & 0.2279 & 0.2305 & 0.2321 & 0.2346 & 0.2376 & 0.2400 & 0.2486 \\
\hline \multirow[t]{2}{*}{ Nanjing } & $\mathrm{C}$ & 0.4601 & 0.4695 & 0.4793 & 0.4870 & 0.4911 & 0.4893 & 0.4923 & 0.4976 & 0.4996 \\
\hline & $\mathrm{D}$ & 0.1748 & 0.1810 & 0.1887 & 0.1955 & 0.2006 & 0.2017 & 0.2062 & 0.2135 & 0.2180 \\
\hline \multirow[t]{2}{*}{ Wuxi } & C & 0.4974 & 0.4982 & 0.5000 & 0.5000 & 0.4998 & 0.5000 & 0.4995 & 0.4989 & 0.4964 \\
\hline & $\mathrm{D}$ & 0.1759 & 0.1835 & 0.1910 & 0.1938 & 0.1940 & 0.1963 & 0.2010 & 0.2041 & 0.2082 \\
\hline \multirow[t]{2}{*}{ Chanzhou } & $\mathrm{C}$ & 0.4275 & 0.4585 & 0.4691 & 0.4692 & 0.4648 & 0.4558 & 0.4796 & 0.4481 & 0.4557 \\
\hline & $\mathrm{D}$ & 0.1466 & 0.1534 & 0.1597 & 0.1623 & 0.1646 & 0.1670 & 0.1783 & 0.1695 & 0.1724 \\
\hline \multirow[t]{2}{*}{ Suzhou } & C & 0.4735 & 0.4681 & 0.4691 & 0.4680 & 0.4642 & 0.4665 & 0.4635 & 0.4629 & 0.4456 \\
\hline & $\mathrm{D}$ & 0.1815 & 0.1868 & 0.1960 & 0.1987 & 0.2020 & 0.2039 & 0.2071 & 0.2095 & 0.2134 \\
\hline \multirow[t]{2}{*}{ Nantong } & C & 0.4946 & 0.4901 & 0.4936 & 0.4964 & 0.4989 & 0.4979 & 0.4960 & 0.4930 & 0.4927 \\
\hline & $\mathrm{D}$ & 0.1532 & 0.1597 & 0.1641 & 0.1677 & 0.1708 & 0.1750 & 0.1803 & 0.1848 & 0.1873 \\
\hline \multirow[t]{2}{*}{ Yangzhou } & C & 0.4737 & 0.4 & 0.4952 & 0.4975 & 0.4985 & 0.4987 & 0.4988 & 0.4992 & 0.5000 \\
\hline & $\mathrm{D}$ & 0.1483 & 0.1517 & 0.1561 & 0.1604 & 0.1628 & 0.1655 & 0.1685 & 0.1724 & 0.1765 \\
\hline \multirow[t]{2}{*}{ Zhengjiang } & C & 0.4699 & 0.4863 & 0.4891 & 0.4935 & 0.4916 & 0.4924 & 0.4955 & 0.4952 & 0.4947 \\
\hline & $\mathrm{D}$ & 0.1551 & 0.1580 & 0.1624 & 0.1679 & 0.1702 & 0.1731 & 0.1774 & 0.1795 & 0.1794 \\
\hline \multirow[t]{2}{*}{ Taizhou (J) } & $\mathrm{C}$ & 0.4841 & 0.4997 & 0.4997 & 0.4998 & 0.4994 & 0.4993 & 0.4988 & 0.4991 & 0.4985 \\
\hline & $\mathrm{D}$ & 0.1393 & 0.1425 & 0.1485 & 0.1536 & 0.1566 & 0.1599 & 0.1647 & 0.1697 & 0.1721 \\
\hline \multirow[t]{2}{*}{ Yancheng } & C & 0.4968 & 0.4993 & 0.4997 & 0.4987 & 0.4983 & 0.4974 & 0.4957 & 0.4964 & 0.4972 \\
\hline & $\mathrm{D}$ & 0.1307 & 0.1358 & 0.1421 & 0.1463 & 0.1500 & 0.1551 & 0.1593 & 0.1625 & 0.1631 \\
\hline \multirow[t]{2}{*}{ Hangzhou } & C & 0.4842 & 0.4820 & 0.4768 & 0.4790 & 0.4795 & 0.4785 & 0.4762 & 0.4705 & 0.4637 \\
\hline & $\mathrm{D}$ & 0.1747 & 0.1815 & 0.1861 & 0.1901 & 0.1925 & 0.1968 & 0.2005 & 0.2027 & 0.2069 \\
\hline \multirow[t]{2}{*}{ Ningbo } & $\mathrm{C}$ & 0.4988 & 0.4984 & 0.4932 & 0.4892 & 0.4945 & 0.4943 & 0.4948 & 0.4945 & 0.4889 \\
\hline & $\mathrm{D}$ & 0.1705 & 0.1801 & 0.1862 & 0.1901 & 0.1912 & 0.1939 & 0.1959 & 0.1985 & 0.2016 \\
\hline \multirow[t]{2}{*}{ Jiaxing } & $\mathrm{C}$ & 0.3343 & 0.3619 & 0.3687 & 0.3677 & 0.3779 & 0.3920 & 0.3953 & 0.3940 & 0.4942 \\
\hline & $\mathrm{D}$ & 0.1957 & 0.1986 & 0.2014 & 0.2042 & 0.2086 & 0.2136 & 0.2172 & 0.2224 & 0.1912 \\
\hline \multirow[t]{2}{*}{ Huzhou } & C & 0.4367 & 0.4433 & 0.4592 & 0.4639 & 0.4720 & 0.4756 & 0.4793 & 0.4805 & 0.4882 \\
\hline & $\mathrm{D}$ & 0.1376 & 0.1426 & 0.1500 & 0.1534 & 0.1590 & 0.1628 & 0.1650 & 0.1687 & 0.1746 \\
\hline
\end{tabular}

2 According to the data set and collation published on the website of the National Bureau of Statistics (2020) 


\begin{tabular}{|c|c|c|c|c|c|c|c|c|c|c|}
\hline \multirow[t]{2}{*}{ Shaoxing } & $C$ & 0.4967 & 0.4959 & 0.4961 & 0.4978 & 0.4973 & 0.4956 & 0.4970 & 0.4998 & 0.4999 \\
\hline & $\mathrm{D}$ & .1460 & 0.1510 & 0.1542 & 0.1614 & 0.1641 & 0.1708 & 0.1802 & 0.1807 & 0.1830 \\
\hline \multirow[t]{2}{*}{ Zhoushan } & $\mathrm{C}$ & 0.3417 & 0.3622 & 0.3613 & 0.3642 & 0.3703 & 0.3702 & 0.3765 & 0.3615 & 0.3577 \\
\hline & $\mathrm{D}$ & 0.1248 & 0.1309 & 0.1327 & 0.1351 & 0.1382 & 0.1397 & 0.1428 & 0.1407 & 0.1423 \\
\hline \multirow[t]{2}{*}{ Taizhou(Z) } & $\mathrm{C}$ & 0.4865 & 0.4921 & 0.4922 & 0.4932 & 0.4933 & 0.4934 & 0.4949 & 0.4950 & 0.4975 \\
\hline & $\mathrm{D}$ & 0.1463 & 0.1511 & 0.1539 & 0.1570 & 0.1605 & 0.1633 & 0.1663 & 0.1697 & 0.1739 \\
\hline \multirow[t]{2}{*}{ Jinhua } & $C$ & 0.4487 & 0.4641 & 0.4761 & 0.4805 & 0.4796 & 0.4780 & 0.4870 & 0.4887 & 0.4957 \\
\hline & $\mathrm{D}$ & 0.1383 & 0.1465 & 0.1531 & 0.1569 & 0.1593 & 0.1615 & 0.1659 & 0.1689 & 0.1739 \\
\hline \multirow[t]{2}{*}{ Hefei } & $\mathrm{C}$ & 0.4961 & 0.4993 & 0.4986 & 0.4968 & 0.4970 & 0.4976 & 0.4974 & 0.4903 & 0.4883 \\
\hline & $\mathrm{D}$ & 0.1566 & 0.1601 & 0.1665 & 0.1707 & 0.1760 & 0.1779 & 0.1818 & 0.1880 & 0.1902 \\
\hline \multirow[t]{2}{*}{ Wuhu } & $\mathrm{C}$ & 0.3806 & 0.4050 & 0.4260 & 0.4376 & 0.4386 & 0.4295 & 0.4305 & 0.4538 & 0.4416 \\
\hline & $\mathrm{D}$ & 0.1441 & 0.1514 & 0.1583 & 0.1641 & 0.1659 & 0.1649 & 0.1677 & 0.1764 & 0.1738 \\
\hline \multirow[t]{2}{*}{ Maanshan } & $C$ & 0.2513 & 0.2816 & 0.3105 & 0.3253 & 0.3281 & 0.3290 & 0.3318 & 0.3428 & 0.3303 \\
\hline & $\mathrm{D}$ & 0.1188 & 0.1267 & 0.1356 & 0.1407 & 0.1432 & 0.1442 & 0.1461 & 0.1504 & 0.1482 \\
\hline \multirow[t]{2}{*}{ Tongling } & C & 0.3726 & 0.3665 & 0.3913 & 0.3854 & 0.3816 & 0.3808 & 0.3702 & 0.3854 & 0.3720 \\
\hline & $\mathrm{D}$ & 0.1287 & 0.1337 & 0.1382 & 0.1426 & 0.1437 & 0.1369 & 0.1383 & 0.1433 & 0.1403 \\
\hline \multirow[t]{2}{*}{ Anqing } & C & 0.2577 & 0.2783 & 0.2908 & 0.3193 & 0.3216 & 0.3064 & 0.3038 & 0.3313 & 0.3394 \\
\hline & $\mathrm{D}$ & 0.1098 & 0.1158 & 0.1196 & 0.1277 & 0.1305 & 0.1281 & 0.1298 & 0.1377 & 0.1433 \\
\hline \multirow[t]{2}{*}{ Chuzhou } & C & 0.3406 & 0.3695 & 0.3931 & 0.4042 & 0.4109 & 0.4000 & 0.3967 & 0.4222 & 0.4372 \\
\hline & $\mathrm{D}$ & 0.1117 & 0.1219 & 0.1304 & 0.1351 & 0.1378 & 0.1365 & 0.1375 & 0.1447 & 0.1509 \\
\hline \multirow[t]{2}{*}{ Chizhou } & C & 0.3444 & 0.3561 & 0.3725 & 0.3770 & 0.3831 & 0.3702 & 0.3702 & 0.3909 & 0.3948 \\
\hline & $\mathrm{D}$ & 0.1031 & 0.1068 & 0.1106 & 0.1128 & 0.1160 & 0.1147 & 0.1162 & 0.1222 & 0.1235 \\
\hline \multirow[t]{2}{*}{ Xuancheng } & C & 0.3896 & 0.4170 & 0.4317 & 0.4335 & 0.4364 & 0.4154 & 0.4208 & 0.4325 & 0.4429 \\
\hline & $\mathrm{D}$ & 0.1099 & 0.1151 & 0.1209 & 0.1239 & 0.1280 & 0.1258 & 0.1296 & 0.1350 & 0.1385 \\
\hline \multirow[t]{2}{*}{ Average } & C & 0.4281 & 0.4392 & 0.4467 & 0.4501 & 0.4516 & 0.4490 & 0.4502 & 0.4531 & 0.4567 \\
\hline & $\mathrm{D}$ & 0.1479 & 0.1535 & 0.1590 & 0.1632 & 0.1661 & 0.1678 & 0.1716 & 0.1752 & 0.1767 \\
\hline
\end{tabular}

3.2.2 Time evolution trend

Comparing the top three cities and bottom three cities ranked by the coupling coordination degree in each year, from Table 6 it is observed that the data from 2010 to 2018 can be divided into two parts by the ranking: (1) From 2010 to 2015, Jiaxing, Yangzhou, and Wuhu have always been in the top three. (2) Things changed a lot in 20162018. The ranking of Hefei, Suzhou, Hangzhou, and Chuzhou has increased significantly. In 2016, Hangzhou, Suzhou, and Hefei are Top three. In 2017, Jiaxing, Yangzhou, and Chuzhou. In 2018, Jiaxing, Chuzhou, and Wuhu.

Table 6. Statistical discriptions of Yangtze River Delta City Group from 2010 to 2018

\begin{tabular}{lllll}
\hline Year & The top three & Average of D & The last three & Average of D \\
\hline 2010 & Shanghai Jiaxing Suzhou & 0.1997 & Chizhou Anqing Xuancheng & 0.1076 \\
2011 & Shanghai Jiaxing Suzhou & 0.2038 & Chizhou Xuancheng Anqing & 0.1126 \\
2012 & Shanghai Jiaxing Suzhou & 0.2084 & Chizhou Anqing Xuancheng & 0.1170 \\
2013 & Shanghai Jiaxing Suzhou & 0.2111 & Chizhou Xuancheng Anqing & 0.1215 \\
2014 & Shanghai Jiaxing Suzhou & 0.2142 & Chizhou Xuancheng Anqing & 0.1248 \\
2015 & Shanghai Jiaxing Suzhou & 0.2174 & Chizhou Xuancheng Anqing & 0.1229 \\
\hline
\end{tabular}




\begin{tabular}{lllll}
\hline 2016 & Shanghai Jiaxing Suzhou & 0.2206 & Chizhou Xuancheng Anqing & 0.1252 \\
2017 & Shanghai Jiaxing Nanjing & 0.2253 & Chizhou Xuancheng Anqing & 0.1316 \\
2018 & Shanghai Nanjing Suzhou & 0.2267 & Chizhou Xuancheng Tongling & 0.1341 \\
\hline
\end{tabular}

\subsubsection{Urban scale characteristics in Yangtze River Delta City Group}

Comparing the top three cities and bottom three cities ranked by the coupling coordination degree in each year, from Table 6, it is observed that the data from 2010 to 2018 can be divided into two parts by the ranking. From 2010 to 2016, the top three have been Shanghai Jiaxing and Suzhou. In 2017, it became Shanghai Jiaxing and Nanjing. In 2018, it became Shanghai Nanjing and Suzhou. During the study period, Chizhou and Xuancheng have been at the lowest level, while Xuancheng, Anqing, and Tongling have also appeared in the last three levels respectively. The average of $\mathrm{D}$ for the first three cities increased from 0.1997 to 0.2267 , an increase of $13.52 \%$. Over the same period, the average of $\mathrm{D}$ for the last three cities also increased from 0.1076 to 0.1341 , an increase of $24.63 \%$. Therefore, the gap between the cities in the Yangtze River Delta city group has a further decreasing trend.

\subsection{Spatial analysis of green innovation and new urbanization coordination}

\subsubsection{Evolution characteristics of spatial distribution differences}

Observing the changing trend of the coupling coordination degree in Table 5 and Figure 4, the three years, 2010, 2014, and 2018, are selected as typical years to analyze the spatial distribution differences of the green innovation and new urbanization coupling coordination degrees for the cities in Yangtze River Delta City Group.

From Figure 5, in 2010, cities in the middle Yangtze River Delta City Group such as Suzhou, Wuxi, Nanjing, Jiaxing, and Hangzhou, in Shanghai of the eastern Yangtze River Delta City Group, had the highest degree of coupling coordination of green innovation and new urbanization development systems, with better development situation in comparison. Other cities in western Yangtze River Delta City Group had poorer coordination.

The same argument, it can be seen from Figure 6 that by 2014, Ningbo City in the eastern Yangtze River Delta City Group entered maintained a high degree of coordination from the previous second tier. Hefei, Zhengjiang, and Nantong get into the second-tier degree of coordination.

From Figure 7, by 2018, the Yangtze River Delta City Group's coordination has been further improving overall, and Within the 26 cities, the gap between the coordination of each other further slowed down. Shanghai has always been the most coordinated, has always been at the top stage, and in 2018 it is the only one. 


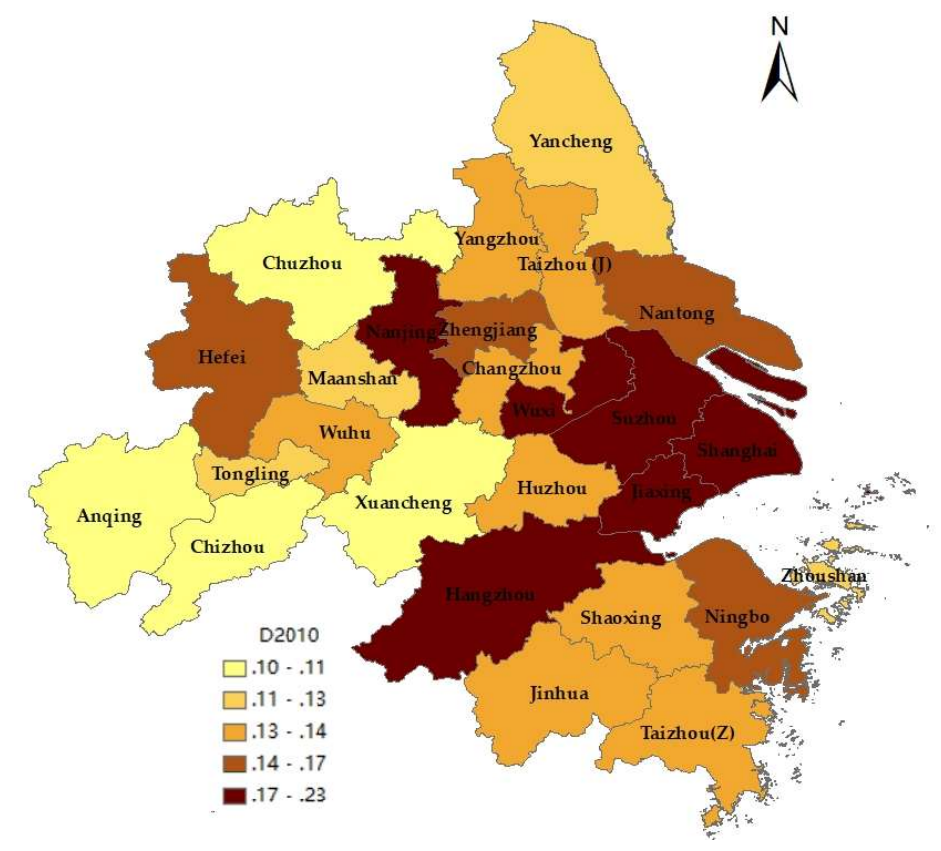

Figure 5. Spatial differences in coordination among cities in Yangtze River Delta City Group in 2010

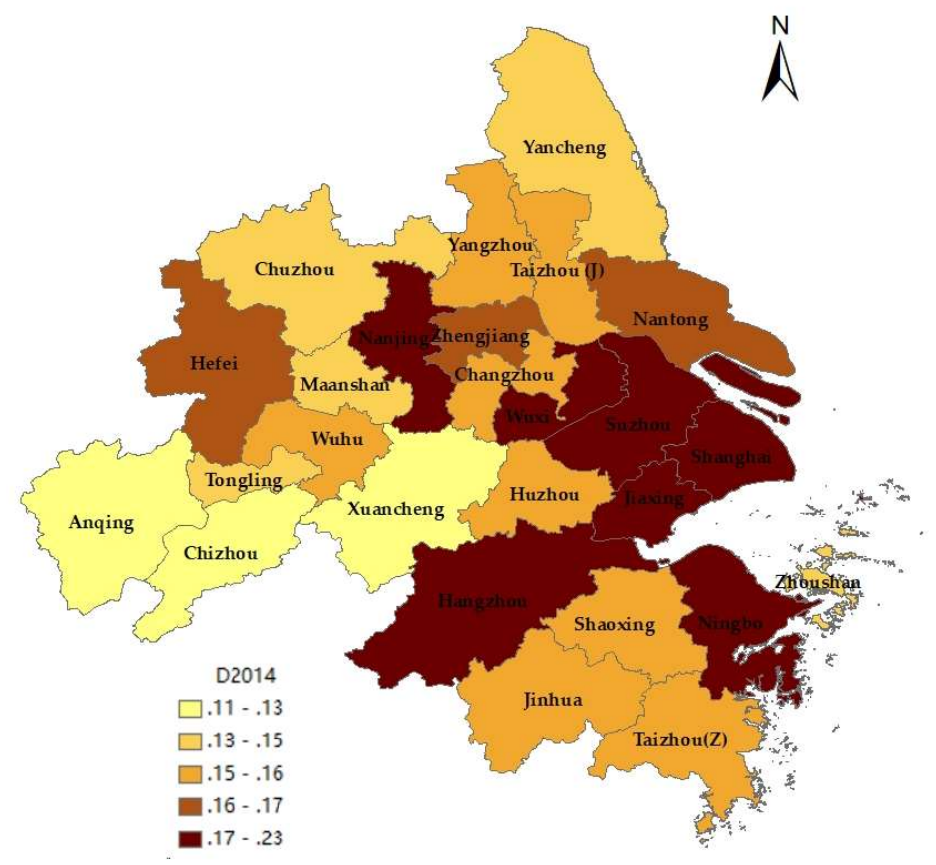

Figure 6. Spatial differences in coordination among cities in Yangtze River Delta City Group in 2014 


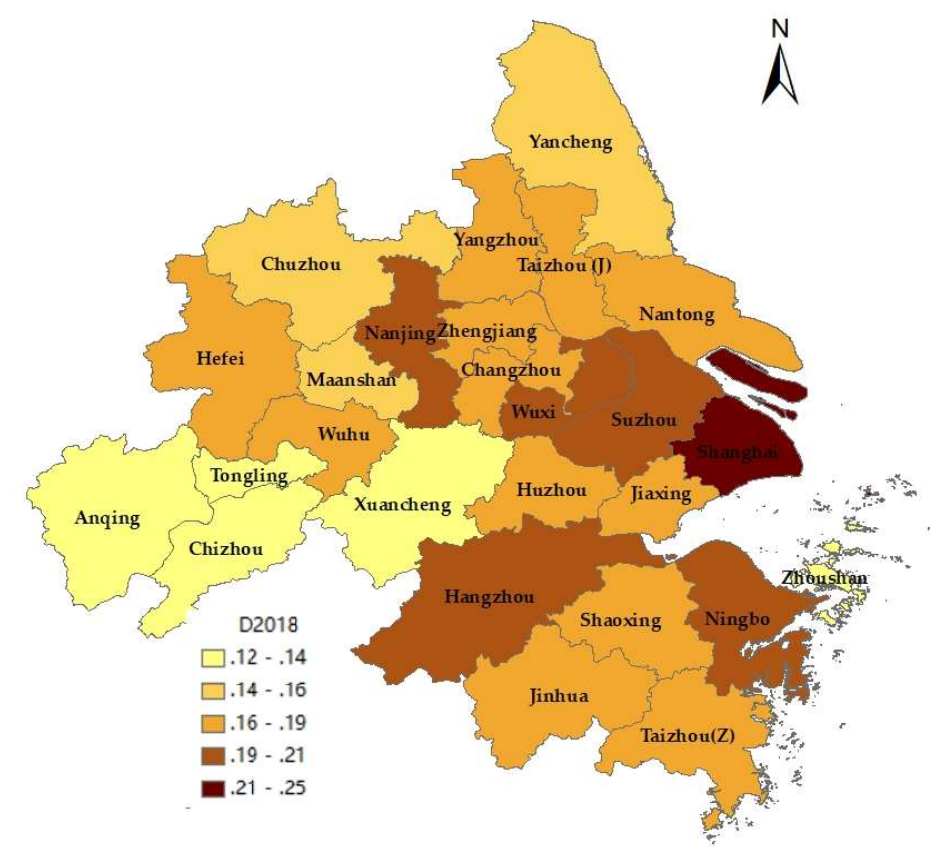

Figure 7. Spatial differences in coordination among cities in Yangtze River Delta City Group in 2018

\subsubsection{Spatial autocorrelation analysis}

Based on the data of the selected 26 cities regarding the green innovation - new urbanization system coordination degree from 2010 to 2018, the spatial correlation of the coordination degree of each city was analyzed.

As shown in Figure 8, where the horizontal axis represents the comprehensive score of the coordination degree between the two systems for the 26 cities in the past 9 years, and the vertical axis denotes the comprehensive score data of the mean coordination degree of the 26 cities from 2010 to 2018 after the spatial weighting calculation, it can be concluded that the coordination index of Yangtze River Delta City Group has certain spatial aggregation, and most of the observed values are located in the first and third quadrant, showing a positive correlation in spatial distribution. This means that green innovation resources input and output can have at least a double effect. First, because inputs and outputs in green innovation promote economic development; Second, As a result of the output of green innovation, technological progress is accelerated, regional economic development level is improved, and environmental pollution is reduced. Hence it has been promoting the development of new urbanization development forming all aspects direct or indirect. 


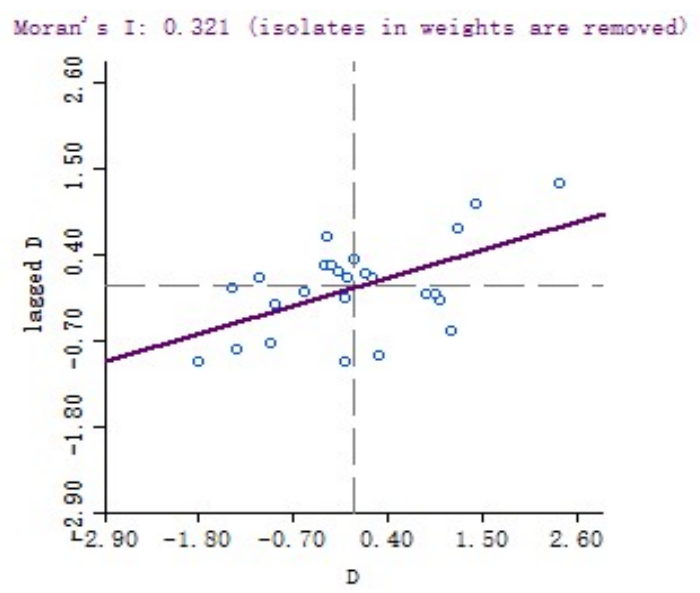

Figure 8. Yangtze River Delta City Group Coupling Coordination Moran Scatter Chart

Figure 9 is a clustering chart for Yangtze River Delta City Group showing the average scores of the coordination index at a significance level of 5\%. It shows that Shanghai, Suzhou, and Jiaxing are of High-High type, Hefei and Nanjing are High-Low type, Anqing, Chizhou, Tongling, and Wuhu are Low-Low type, and the correlations among other cities are not very prominent. Through the spatial correlation analysis of the coordination degree of the cities, the following conclusions are drawn:

(1) from 2010 to 2018, the cities with a relatively high degree of coordination of the green innovation and new urbanization system are Suzhou, Jiaxing, and Shanghai. Comparatively speaking, the coordination between Wuxi and Suqian is lower, and the degree of coordinated development is not good, but the coordinated governance capabilities of the nearby areas are stronger. These cities should keep pace and proactively move to neighboring cities. Learn from experience, to improve the ability of coordinated governance of the environment-economic system and improve the level of coordinated development in the region.

(2) The level of coordination of the green innovation-new urbanization system in Yangtze River Delta City Group shows some positive correlation, and the correlation is not strong, indicating that the synergy between the new urbanization development and the green innovation of cities does not display a particularly obvious spatial agglomeration. It can be seen that the construction of the cooperative mechanism in Yangtze River Delta City Group is still in its infancy, and the spatial concentration force between regions is not large. This also reflects some extent the gaps in development levels between local cities, and the external effects between regions are not strong. 


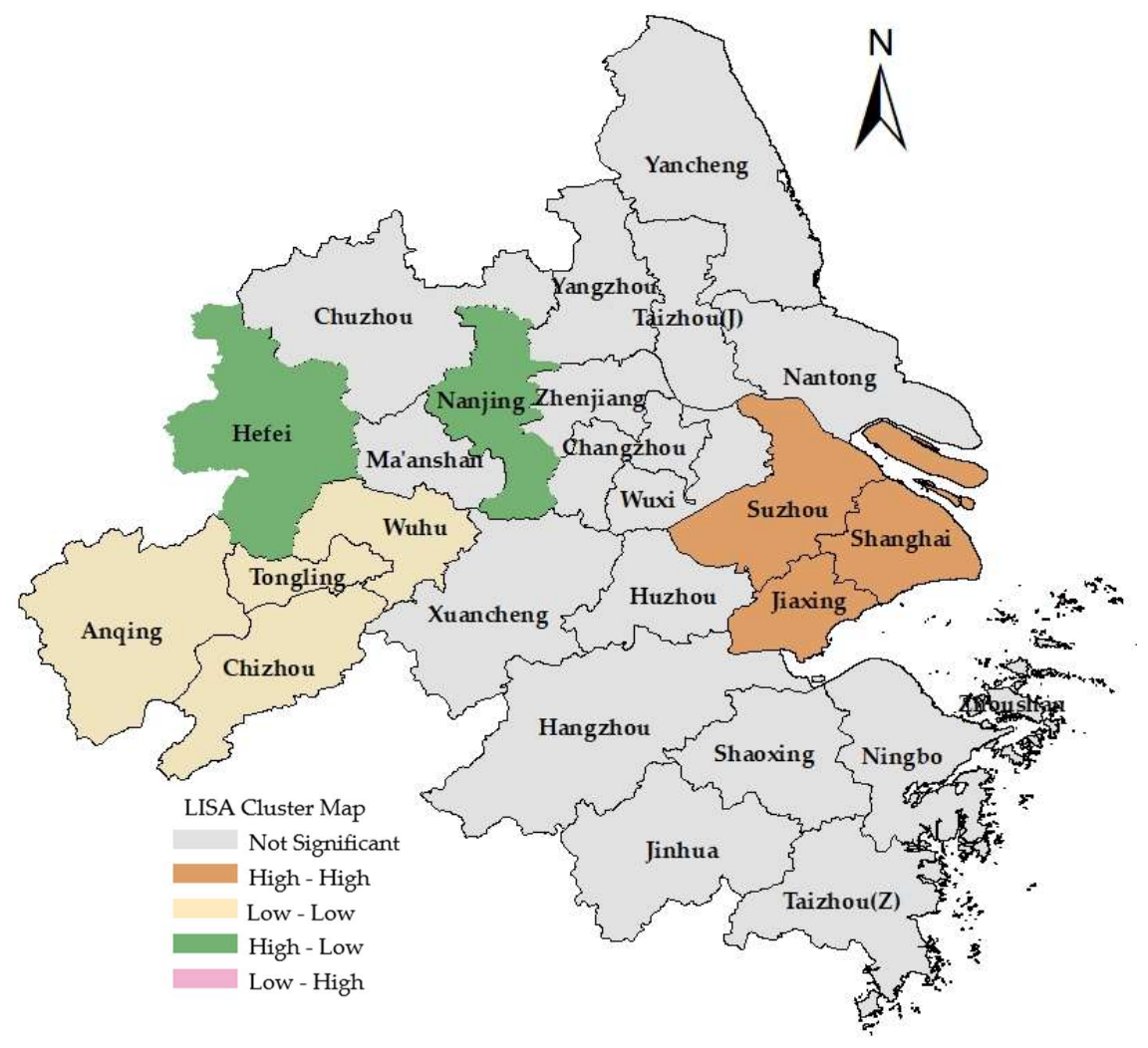

Figure 9. Yangtze River Delta City Group LISA Cluster Map

\section{Discussion}

4.1 Green innovation promotes the development of new urbanization and there is a synergistic effect between the two

Urbanization development should rely on technological progress, and promote economic growth and urbanization through technological progress [8]. Wilson [9] analyzed that technological innovation is the source of power to promote the development of urbanization. Green innovation is based on the regional science and technology innovation system, which highlights the friendliness and sustainability of the environment. Therefore, indicator factors such as environmental friendliness and sustainability are highlighted in the measurement indicators of the green innovation system. The new urbanization is a complex system, which is quite different from the traditional ones that used the only population as the measurement index, which includes urbanization of the population, economic urbanization, spatial urbanization, social urbanization, Ecological urbanization, and environmental pollution. What is the relationship between the two systems of green innovation and new urbanization? To understand how the relationship between the two becomes meaningful. From the perspective of the coupling degree model, according to table 4 , it can be known that there is a coupling development between green innovation and new urbanization development. The coupling degree between the two has always been maintained at about 0.45 , and the coupling coordination degree has been improved year by year during the study period. Therefore, there is a clear interaction between the two systems. It can also be seen from the relative development speed of the two systems $\varphi([0.881 .09])$ that its value always remains within $0.8-1.2$ within the synchronous development interval. Therefore, the synchronization effect of the two is obvious. Previous studies have shown that technological innovation has a significant positive effect on the 
quality of the development of new urbanization. The communication and mutual promotion mechanism between the two systems has not been fundamentally changed due to the addition of green indicators. However, compared with the impact of technological innovation on new urbanization, green innovation has certain differences in the degree of coupling, coordination, and relative development speed of new urbanization. This may be mainly because factors such as environment and sustainability have weakened the interaction between the two.

4.2 The intensity and coordination of the interaction between green innovation and new urbanization are affected by the level of economic development.

Tian [39] found that there is an interaction between new urbanization and technological innovation, which is manifested as a positive bilateral impact. The coordination between the two is affected by the regional economic level, and the less developed regions have an impact on the new technological innovation level. The greater the role of urbanization. Taking each city in the Yangtze River Delta city group as a sample, it is found that the coupling degree of green innovation and new urbanization has declined in 7 of the 26 cities in the Yangtze River Delta city group. These 7 cities are all above the trillion levels that belong to the first echelon economically. According to data released by the National Bureau of Statistics in 2020, there are 16 cities in China with a GDP exceeding one trillion yuan, of which 8 out of 26 cities in the Yangtze River Delta city group. It can also be seen from Table 6 that the level of economic development will affect the degree of coupling and coordination between the two. The higher the economic level, the coupling degree of the interaction of the two systems decreases, while the coupling coordination degree further improves.

4.3 Green innovation and new urbanization have a positive spatial correlation and regional agglomeration

It can be seen from figure 8 that the global Moran's I index reflecting the spatial autocorrelation is 0.321 , indicating that there is a positive spatial correlation, and the correlation coefficient is 0.321 . From figure 9 Lisa cluster map, it can be found that there are highhigh, low-low, and high-low clusters; From the perspective of the temporal development of space, Jiaxing's coupling coordination has been maintained at a relatively high level, thanks to the influence of the spatial spillover effects in surrounding Suzhou and Shanghai. It can be found from figure 5 - figure 7 and table 6 that the overall overflow benefit of the space is obvious and the internal economic development level is an important factor that affects the coupling coordination of green innovation and new urbanization, and its effect exceeds the external spatial effect.

\section{Conclusions}

The relationship between green innovation and new urbanization has not been thoroughly and systematically analyzed and discussed inner and outer in depth. This article first builds a scientific indicator system for green innovation and new urbanization based on existing literature and research results, innovatively analyzes the internal relationship of the green innovation-new urbanization system from the perspective of coupling and coordination, and combines the external relationship of these two methods to further explain whether green innovation can promote new urbanization development and how to promote new urbanization development. Taking Yangtze River Delta City Group as an example, the green innovation and new urbanization development and the coupling and coordination relationship during the 9 years from 2010 to 2018 were evaluated, and their temporal and spatial characteristics and evolution laws were investigated. The main conclusions are as follows: (1). Green innovation has facilitated the development of new urbanization, and at the same time, new urbanization has also provided beneficial support 
for green innovation. Therefore, there is a synergy between the two and advances in the interval of simultaneous development. For this reason, green innovation and new urbanization must be supported simultaneously and achieve coordinated and synchronized development. (2). The interaction and coordination degree of green innovation and newtype urbanization are affected by the level of regional economic development, and its influence is higher than the spatial effect between adjacent cities. Based on this conclusion, the degree of interaction and the degree of coupling coordination in each region are different, and corresponding measures should be taken according to the actual conditions of each region and country to ensure green and sustainable development. (3). In space, there is a positive relationship between neighbors and high-high, low-low, and high-low clusters.

Author Contributions: Weixiang Xu carried out the conceptual design and overall layout, Lindong Ma participated in the overall layout, data collection, and writing, Yuanxiao Hong participated in the writing, Xiaoyong Quan provided some opinions and revised the full text. All authors have read and agreed to the published version of the manuscript.

Funding: This research received no external funding.

Data Availability Statement: The data required in this study were all from the official statistical yearbook and statistical bulletin.

Acknowledgments: The authors would like to thank Dr. Xihui Chen, Dr. Wenhao Mao, Dr. Xinyun Dai, and Dr. Hangxin Huang for the paper suggestions, and the authors would also like to acknowledge the financial support received from the following resources: National Social Science Fund Major Project of China (18ZDA045).

Conflicts of Interest: The authors declare no conflict of interest.

\section{Referencese}

1. Zhiduan, C. Green Eco-City Development Under the Background of the New Urbanization. Urban Development Studies 2015, 22, 1-7.

2. Xingbo, W. On the Main Theories Innovation of A Report at the 19th National Congress of the Communist Party of China. Journal of Kaili University 2018, 36, 5-8.

3. Liu, Y.; Zhu, J.; Li, E.Y.; Meng, Z.; Song, Y. Environmental regulation, green technological innovation, and eco-efficiency: The case of Yangtze River economic belt in China. Technol. Forecast. Soc. Chang. 2020, 155, 119993.

4. Yanbing, M.; Yunke, Y. An Empirical Study of the Impact of New Green Urbanization on Economic Growth. Journal of Shanghai University(Social Sciences Edition) 2019, 36, 107-118, doi:10.3969/j.issn1007-6522.2019.06.009.

5. Ren, Y.; Wang, C. Empirical Study on Impact of Urbanization on Regional Green Economic Efficiency in China. Technology Economics 2017, 36, 72-98.

6. Jingxiao, Z.; Runchang, L. Evolution of Urban Green Innovation Efficiency Under Environmental Regulations: A Case Study of Xi'an. Urban and Environmental Studies 2019, 4, 34-50.

7. Zhou, D.; Lin, Z.; Ma, S.; Qi, J.; Yan, T. Assessing an ecological security network for a rapid urbanization region in Eastern China. Land Degradation \& Development 2021, doi:10.1002/ldr.3932.

8. J, G. The evolution of inhaler technology. The Journal of asthma: official journal of the Association for the Care of Asthma $1994,1$.

9. Wilson, R.P.; Vandenabeele, S.P. Technological innovation in archival tags used in seabird research. Marine Ecology Progress Series 2012, 451, 245-262, doi:10.3354/meps09608.

10. Shunfei, L.; Shengyuan, X.; Fayuan, W. Analysis on the Effect of S\&T Investment and Public Support on Urbanization Based on the Empirical Analysis of 11 Provinces and Cities Spatial Dubin Model in Yangtze River Economic Zone. Science $\mathcal{E}$ Technology Progress and Policy 2019, 36, 57-64.

11. Jacobs, J. The economy of cities; Random House: New York, 1969. 
12. Rosenthal, S.S.; Strange, W.C. Chapter 49 Evidence on the Nature and Sources of Agglomeration Economies. In Handbook of Regional and Urban Economics, J. Vernon Henderson, J.-F.T., Ed.; Elsevier: The Kingdom of the Netherlands, 2004; Volume 4. 2119-2171.

13. Tappeiner, G.; Hauser, C.; Walde, J. Regional knowledge spillovers: Fact or artifact? Research Policy 2008, 37, 861-874, doi:10.1016/j.respol.2007.07.013.

14. Xianyou, D.; wen, X.; Ze, T. Study on the Synergistic Effect of Industry's Green and Innovation Development in Yangtze River Delta Urban Agglomeration. Journal of Industrial Technological Economics 2019, 309, 67-75.

15. Q., K.L.W.Y.C. A Summary of the Yangtze River Delta High-quality Integrated Development Forum. Regional Economic Review 2019, 5, 145-150, doi:10.14017/j.cnki.2095-5766.20190923.019.

16. China, S.o.t.P.s.R.o. Reply of the State Council on the Development Plan of the Yangtze River Delta Urban Agglomeration. 2016, 16, 26-26.

17. Zhou, X.; Yu, Y.; Yang, F.; Shi, Q. Spatial-temporal heterogeneity of green innovation in China. Journal of Cleaner Production 2021, 282, doi:10.1016/j.jclepro.2020.124464.

18. Peng, Y.; Shuguang, L.; Cai, C. Efficiency Measurement and Obstacle Indicators of Urbanization in China's Coastal Urban Agglomerations. East China Economic Management 2017, 31, 68-74, doi:10.3969/j.issn.1007-5097.2017.07.009.

19. Jianshuang, F.; Xiaofen, Y.; Lihua, Z. Comprehensive Efficiency Level and Driving Factors of China's Regional Urbanization. Scientia Geographica Sinica 2015, 35, 1077-1085, doi:10.13249/j.cnki.sgs.2015.09.002.

20. Chuanglin, F.; Xingliang, G. Comprehensive measurement and spatial distinction of input-output efficiency of urban agglomerations in China. ACTA GEOGRAPHICA SINICA 2011, 66, 1011-1085.

21. Zhengyun, J.; Yan, H. Coupling and coordination between new urbanization and agricultural modernization in Central China. Journal of Natural Resources 2021, 36, 702-721, doi:10.31497/zrzyxb.20210313.

22. Faming, Z.; Jinping, Y.; Xiaopang, W. Coupling and coordination analysis of new-type urbanization quality and ecoenvironmental carrying capacity: A case study in central China. Ecological Economy 2021, 37, 63-69.

23. Li, M.; Du, Y.; Fang, X. CONTRIBUTION OF HIGH-SPEED RAIL (HSR) TO REGIONAL TOURISM DEVELOPMENT: CASE STUDY OF THE HSR NETWORK IN CHINA. Transformations in Business E Economics 2020, 19, 188-205.

24. Zhang, Y.; Sun, M.; Yang, R.; Li, X.; Zhang, L.; Li, M. Decoupling water environment pressures from economic growth in the Yangtze River Economic Belt, China. Ecological Indicators 2021, 122, doi:10.1016/j.ecolind.2020.107314.

25. Zhang, J.; Ouyang, Y.; Ballesteros-Pérez, P.; Li, H.; Skitmore, M. Understanding the Impact of Environmental Regulations on Green Technology Innovation Efficiency in the Construction Industry. Sustainable Cities and Society 2020, $65,102647$.

26. Yi, M.; Wang, Y.; Yan, M.; Fu, L.; Zhang, Y. Government R\&D Subsidies, Environmental Regulations, and Their Effect on Green Innovation Efficiency of Manufacturing Industry: Evidence from the Yangtze River Economic Belt of China. International Journal of Environmental Research and Public Health 2020, 17, 1330, doi:10.3390/ijerph17041330.

27. Feng, C.; Shi, B.; Rong, K. Does Environmental Policy Reduce Enterprise Innovation? - Evidence from China. Sustainability 2017, 9, 872, doi:10.3390/su9060872.

28. Yingwen, Z.; Huoming, L. Coupling Mechanism of New Urbanization and Agricultural Modernization in China. Journal of Capital University of Economics and Business 2016, 18, 3-10, doi:10.13504 /j.cnki. issn1008-2700.2016.03.001.

29. Xiaonan, C. Expression and Mathematical Property of Coupling Model, and Its Misuse in Geographical Science. Economic Geography 2019, 39, 18-25, doi:10.15957/j.cnki.jjdl.2019.04.003.

30. Liming, X.; Xianpeng, Z. Spatio-temporal characteristics of coupling coordination between green innovation efficiency and ecological welfare performance under the concept of strong sustainability. Journal of Natural Resources 2019, 34, 312-324, doi:10.31497/zrzyxb.20190208. 
31. Sun, H.; Huang, Z.; Dongdong, X.U.; Shi, X.; Liu, H.; Tan, L.; Junlian, G.E. The Spatial Characteristics and Drive Mechanism of Coupling Relationship between Urbanization and Eco-Environment in the Pan Yangtze River Delta. Economic Geography 2017, 37, 163-186, doi:10.15957/j.cnki.jjdl.2017.02.022.

32. Zhu, Y.; He, G.; Zhang, G.; Bao, K.; Wang, X. Research on coupling coordination and spatial differentiation of new-type urbanization and ecological environment in Wanjiang demonstration area. GeoJournal 2020, 1-13, doi:10.1007/s10708-02010324-y.

33. Nelson, K.S.; Nguyen, T.D.; Brownstein, N.A.; Garcia, D.; Walker, H.C.; Watson, J.T.; Xin, A. Definitions, measures, and uses of rurality: A systematic review of the empirical and quantitative literature. Journal of Rural Studies 2021, 82, 351-365, doi:10.1016/j.jrurstud.2021.01.035.

34. Qingyu, F.; Shan, Y.; Xin, H. Temporal and spatial characteristics and interaction process of urbanization coordination in the Yangtze River Delta region from the perspective of coupling. GEOGRAPHICAL RESEARCH 2020, 39, 289-302, doi:10.11821/dlyj020181167.

35. Peng, B.; Sheng, X.; Wei, G. Does environmental protection promote economic development? From the perspective of coupling coordination between environmental protection and economic development. Environ Sci Pollut Res Int 2020, doi:10.1007/s11356-020-09871-1.

36. Zhong, S.; Xiong, Y.; Xiang, G. Environmental regulation benefits for whom? Heterogeneous effects of the intensity of the environmental regulation on employment in China. J. Environ. Manage. 2021, 281, 111877-111877, doi:10.1016/j.jenvman.2020.111877.

37. Linjian, C.; Jie, W.; Huanghuang, W.; Huihui, C. Evolutional Analysis of Coupling between Infrastructure and Population Agglomeration in Beijing-Tianjin-Hebei region -- Analysis Based on Push-pull Theory. Scientia Geographica Sinica 2019, 39, 1256-1264, doi:10.13249/j.cnki.sgs.2019.08.007.

38. Linjian, C.; Ankang, Y. On coupling coordination degree of technological innovation and new urbanization: A case study of the Beijing-Tianjin-Hebei Region. Science \& Technology Review 2020, 38, 111-120, doi:10.3981/j.issn.1000-7857.2020.15.012.

39. Yipiao, T.; Xiuchuan, X.; Lvjie, X.; Minyue, L.; Weiguo, Z. Regional Difference of Dynamic Relationship between Technological Innovation and the New Urbanization: PVAR Analysis Based on Provincial Panel Data. Science $\mathcal{E}$ Technology Progress and Policy 2016, 33, 42-50, doi:10.6049/kjjbydc.2016030798. 